\title{
BMJ Open Evaluation of the COPING parent online universal programme: study protocol for a pilot randomised controlled trial
}

\author{
Dawn Adele Owen, ${ }^{1}$ Nia Griffith, ${ }^{1}$ Judy Hutchings ${ }^{2}$
}

To cite: Owen DA, Griffith N, Hutchings J. Evaluation of the COPING parent online universal programme: study protocol for a pilot randomised controlled trial. BMJ Open 2017;7:e013381. doi:10.1136/ bmjopen-2016-013381

- Prepublication history and additional material are available. To view these files please visit the journal online (http://dx.doi. org/10.1136/bmjopen-2016013381)

Received 8 July 2016 Revised 27 February 2017 Accepted 8 March 2017

\section{CrossMark}

${ }^{1}$ Department of Psychology, Bangor University, Bangor, Gwynedd, UK

${ }^{2}$ School of Psychology, Bangor University, Bangor, Gwynedd, UK

Correspondence to

Miss Dawn Adele Owen;

dawn.a.owen@bangor.ac.uk

\section{ABSTRACT}

Trial sponsor Bangor University, Brigantia Building, College Road, Bangor, LL57 2AS, UK

Introduction The COPING parent online universal programme is a web-based parenting intervention for parents of children aged 3-8 years with an interest in positive parenting. The programme focuses on strengthening parent-child relationships and encouraging positive child behaviour. This trial will evaluate whether the intervention is effective in increasing the use of positive parenting strategies outlined in the programme using parent report and blind observation measures.

Methods and analysis This is a pilot randomised controlled trial with intervention and wait-list control conditions. The intervention is a 10-week online parenting programme to promote positive parent-child relations by teaching core social learning theory principles that encourage positive child behaviour, primarily through the use of praise and rewards. Health visitors and school nurses will circulate a recruitment poster to parents of children aged 3-8 years on their current caseloads. Recruitment posters will also be distributed via local primary schools and nurseries. Parents recruited to the trial will be randomised on a 2:1 ratio to intervention or wait-list control conditions (stratified according to child gender and age). The primary outcome measure is positive parenting as measured by a behavioural observation of parent-child interactions using the Dyadic Parent-Child Interaction Coding System. Secondary outcomes include parent report of child behaviour, and self-reported parental sense of competence, parenting behaviour and parental mental health. Data will be collected at baseline and 3 months later (postintervention) for all participants and 6 months postbaseline for the intervention group only. Analysis of covariance will be the main statistical method used. Ethics and dissemination The trial has received ethical approval from the NHS Betsi Cadwaladr University Health Board Ethics Committee (REC) and the School of Psychology, Bangor University REC (15/WA/0463). Publication of all outcomes will be in peer-reviewed journals and conference presentations.

Trial registration number Current Controlled Trials ISRCTN89370147 (5 May 2016).

\section{BACKGROUND}

Societal changes are presenting new challenges for parents that can impact on

\section{Strengths and limitations}

This is a randomised controlled trial with a wait-list control group.

- The behavioural observations will incorporate an inter-rater reliability component $(20 \%$ of all observations at each time point).

- Once randomised, intervention parents start the online programme immediately, thus reducing the amount of time spent waiting for the intervention.

- A limitation of this study is internet based only without any additional support and parents are required to log in each week and engage with the programme. This may result in some parents not fully engaging and the potential loss of follow-up data.

- Due to time and funding constraints, this pilot trial aims to enrol 60 parents, which is a fairly small sample size not based on a power calculation.

- Funding and time constraints do not allow for a follow-up beyond 6 months.

parent-child relations, child behaviour and parenting style. For example, increased time spent playing video games impacts on child mental health and social relationships ${ }^{1}$ and changes in marital status/family structures including divorce affect children's social and emotional competence ${ }^{2}$ and can reduce parental competencies. ${ }^{3}$ Dysfunctional parenting is a key factor in the subsequent development of problematic child behaviour. $^{4}$

Minor child problem behaviours can develop into significant problems unless addressed while children are still young. ${ }^{5}{ }^{6}$ Conduct problems have a significant impact on children's functioning and quality of life $^{7}$ with up to $50 \%$ of children and young people with conduct disorder developing antisocial personality disorder. ${ }^{78}$ It is therefore important to provide early universal support to all parents to help them to address the small behavioural challenges faced by 
parents and prevent them from progressing into longerterm ones.

Increases in the numbers of children with identified early onset of behavioural difficulties have resulted in health visitors and school nurses spending much of their time supporting families with children at significant risk of poor outcomes, ${ }^{9}$ reducing their ability to provide more general support to all families. ${ }^{10}$ A survey of health visitors and school nurses reported that $53 \%$ of health visitors saw between 21 and 50 , and $46 \%$ of school nurses saw between 50 and 99 children with emotional or behavioural problems each week. ${ }^{9}$ These growing demands on health visitors and school nurses' time reduces their ability to support all parents at a time when parents are bringing up children in a rapidly changing world with additional challenges. ${ }^{1}$

The positive parenting practices that support children's development are well established ${ }^{11}$ and these include relationship building strategies through time spent in play or joint activities with children, praise and reward to encourage positive child behaviour and positive parental role modelling. ${ }^{12}$ However, evidence-based support for parents is not universally available and changing demands on parents make it important to provide all parents with access to evidence-based information.

Technology has the potential to provide knowledge about key parenting skills, reduce pressures on services; particularly those delivered by heath visitors and school nurses, and offer flexible access. ${ }^{13-15}$ Access to technology is now feasible for many parents due to increased availability of the internet. ${ }^{16}$ In 2016, $89 \%$ of households in Great Britain (23.7 million) had access to the internet, an increase from $86 \%$ in $2015 .{ }^{17}$ The majority of parents $(75 \%)$ now use social media to obtain parent-related information ${ }^{18}$ with over 8 million people visiting an online parenting information and advice website every month. ${ }^{19}$

The accessibility and convenience of access to the web has introduced the opportunity for web-based delivery preventive behavioural interventions for health promotion. ${ }^{20}{ }^{21}$ Accessing the internet has become easier with cheaper internet providers and the availability of devices such as mobile phones and tablets. The internet provides individuals with a useful source of advice and/or support, and offers convenient and flexible access within the home. This has the potential to reduce the burden on healthcare service providers. ${ }^{22}$

Although limited in number, web-based interventions have been shown to be effective in achieving a wide range of positive outcomes to promote healthy behaviours including smoking cessation and weight loss, ${ }^{23-25}$ suggesting that the web is an effective means of providing behaviour change advice. There is evidence demonstrating increased positive parenting following web-based interventions, ${ }^{26}$ however, high attrition rates have been reported, ${ }^{27}$ with many participants starting, but not completing programmes. ${ }^{13}$ Universal parenting programmes in general, including web-based, have not yet been extensively researched. ${ }^{28}$
Early indications have suggested potential benefits of web-based support; ${ }^{26}$ however, more research is needed.

\section{Rationale}

The Coping (Confident Parent Internet Guide) web-based parenting programme is based on the content of 'The Little Parent Handbook', ${ }^{12}$ and provides information and activities based on core social learning theory principles associated with positive parenting practices and good child outcomes to parents of children aged 3-8 years. The study will explore the delivery of the programme, parental satisfaction and engagement with the programme and whether it is effective in demonstrating increased use of positive parental practices in parents of children with a wide age range and varying behavioural patterns.

\section{AIMS AND OBJECTIVES}

The aim of this trial is to conduct a pilot randomised controlled trial on the effectiveness of an online parenting programme, for parents of children aged 3-8 years who would like to learn more about positive parenting by comparing outcomes for intervention and wait-list control conditions.

The key objectives are to establish whether the programme successfully engages and retains parents; whether the programme produces statistically significant increases in positive parenting as observed in a parentchild observation when compared with wait-list control parents; and to determine whether the online programme produces any changes in secondary outcomes (parent-reported child behaviour, parent self-reported sense of competence, behaviour and mental health). The study hypotheses are:

i. The online parenting programme will lead to significant increases in the use of positive parenting strategies as displayed in the behavioural observation coded using Dyadic Parent-Child Interaction Coding System. ${ }^{29}$

ii. The online programme will significantly increase positive self-reported parenting skills, parental sense of competence and parental mental health.

iii. The online programme will lead to reduction in parent-reported levels of child problem behaviour as reported using the Eyberg Child Behaviour Inventory (ECBI) ${ }^{30}$

\section{METHODS/DESIGN}

\section{Trial design}

This pilot RCT will explore the effectiveness of an online parenting programme. Parents of children aged 3-8 years who would like to learn more about positive parenting will be randomly allocated to the intervention condition with immediate access to the programme or to a 3-month wait-list control condition on a 2:1 ratio. Self-report and observational data will be collected in parents' homes 
during home visits and parents will access the programme at home.

\section{Eligibility criteria}

To be eligible for the study, parents must have a child aged between 3 and 8 years, be able to understand English (as the programme is only currently available in English) and be able to access the internet on a PC, laptop or tablet. The software does not yet support smartphones. Parents who are currently receiving support from services are also invited to participate (they will be asked to record which services they are receiving and the duration). Individuals will be excluded from the study if a parent does not have a child aged between 3 and 8 years, does not understand English and does not have access to the internet.

\section{Recruitment}

Health visitors and school nurses in Gwynedd and Anglesey (North-West Wales) will approach parents of children aged 3-8 years on their own caseloads and describe the online programme and the research trial. If parents decide that they might want to sign up for the study, they will be asked by the health visitor/school nurse to complete a note of interest form, which will be sent to the research office at Bangor University, giving consent for a member of the research team to contact the parent.

On receipt of the note of interest form, a member of the research team will contact the parent to arrange a convenient time to visit and discuss the project further. The researcher will go through the information sheet with the parent during this home visit and ensure that any questions are answered. If the parent is happy to continue, the researcher will obtain informed consent from the parent to participate in the study. Only when consent has been obtained (see online supplementary file) will the researcher proceed to ask the parent to fill out the self-report measures and take part in a $30 \mathrm{~min}$ behavioural observation.

In addition to health visitors and school nurses approaching parents on their caseloads, recruitment posters will be distributed in primary schools and nurseries in Gwynedd, Anglesey, Conwy and Denbighshire. An email address and a contact telephone number will be provided on the recruitment poster so that interested parents can contact the research team directly. Parents will either be sent a detailed information sheet via email or the researcher will discuss the study in depth over the telephone. If parents would still like to participate, arrangements will then be made for a home visit to discuss the study further. Similarly, parents who hear about the study through word of mouth can contact the research team for further information regarding the trial.

It is expected that both forms of recruitment (poster and health visitor/school nurse) will attract parents from varying socioeconomic backgrounds who are experiencing varying levels of child problem behaviour. For the purpose of this pilot trial, baseline characteristics of all parents will be reported and compared with the population as a whole. Additionally, the percentage of parents recruited from each source will be reported and their characteristics compared in order to explore the effects of the intervention for the whole sample.

\section{Intervention}

Trials conducted by Hutchings et al during the $1990 \mathrm{~s}^{31}{ }^{32}$ with parents and health visitors demonstrated positive outcomes from teaching effective behavioural strategies to parents of children with challenging behaviour for both clinically referred and preschool prevention populations. Significant overall improvements were found for intervention families on measures of child behaviour, parenting practices and maternal mental health. ${ }^{31}{ }^{33}$ As part of these trials, intervention parents were provided with help sheets that were subsequently published as 'The Little Parent Handbook'. ${ }^{12}$ These trials were multicomponent trials and so it is difficult to establish the true extent of the effectiveness of the parent help-sheets; however, they contained the evidence-based behavioural principles on which the interventions were based.

The LifeGuide software, developed at the University of Southampton, ${ }^{34}$ was used in the creation of the online parenting programme. The aim of LifeGuide is to continuously develop, evaluate and disseminate a set of tools that will allow researchers to flexibly create and modify online behaviour change interventions. ${ }^{35}$ LifeGuide software allows researchers to deliver behavioural principles both through programme delivery (text message prompts, etc) and programme content (The Little Parent Handbook).

Features of the online parenting programme include automated feedback based on individual performance, online praise messages for spending time with their child, text message reminders to access the next session and multiple-choice quizzes to test knowledge. The programme also enables the tracking of individual usage data (which can be extracted into Microsoft Excel), including the number of log in, time spent on each page and the number of chapters completed.

The programme introduces evidence-based behavioural principles that have been shown to be effective in strengthening parent-child relations and encouraging positive child behaviour. ${ }^{36} \mathrm{~A}$ small-scale feasibility study of the online parenting programme was conducted at the end of 2015 with the aim of providing user feedback prior to conducting this pilot RCT trial. The study had no measures and participants were not randomised, instead 20 participants were asked to complete the intervention and fill out a feedback form. Overall, feedback was very positive with the majority of participants reporting that they would recommend the programme to parents of children aged 3-8 years. Minor modifications were made based on the feedback, these include text message prompting to remind parents to log-in to subsequent sessions, more video examples of positive parenting and the option to look back over previously completed chapters again. The intervention consists of 10 chapters, 8 content and 2 revision chapters. The topics are: 
i. Spending special time with your child through play

ii. Encouraging good behaviour through praising

iii. Encouraging good behaviour through rewarding

iv. How to get better at giving instructions (part 1)

v. How to get better at giving instructions (part 2)

vi. Revision (a review of chapters 1-5)

vii. Ignoring problem behaviour

viii. Teaching your child new behaviours

ix. How to develop your child's language skills

x. Revision (a review of chapters 1-9)

Intervention parents will be provided with a link to the website and a username and password. Contact details of an administrator will be provided in case any parent requires technical support during the programme. Parents will be asked to $\log$ in and complete one chapter each week, each chapter will take approximately $30 \mathrm{~min}$ to complete. The software ensures that parents have completed each chapter before they can move on to the next one; they are not required to complete the chapter in one sitting. Log in details allow parents to access the programme as many times as they wish. The intervention has been programmed to take parents to the last page that they viewed on the next occasion that they log in to avoid parents having to start the programme from the beginning. In order to give parents sufficient time to practice the principles outlined in the individual chapters, the intervention has been programmed so that there will be a minimum 5-day gap between each chapter. If parents $\log$ in before the 5 days have elapsed, they will be offered the opportunity to look back over previously completed chapters again.

The programme asks parents to practice the skills presented in the chapter with their child at home. Each chapter concludes with a suggested practice activity. Parents are also encouraged to keep paper records detailing their activities. Parents can also record online each week how many times they have played with their child by selecting the amount of times from a drop-down menu. The programme encourages parents to spend more time playing with their child in order to strengthen their relationship, and they are continuously reminded to engage in this activity throughout the programme both by praise messages and by being prompted to record the amount of time spent playing. A praise message congratulates the parent for spending time with their child if they report spending time with their child during the past week, or since the last time they logged in. If parents do not report having spent time with their child during the past week, a prompt message appears reminding them of the importance of this activity.

Each chapter covers an individual behavioural principle that aims to strengthen the parent-child relationship. Parents read through information (or listen via an audio button if they prefer) and watch video examples of positive parenting. The video clips are short in length (all are $<1 \mathrm{~min}$ long) allowing the opportunity for multiple viewing. At the end of each chapter, there is a longer video and parents are asked to answer three questions based on the video clip (by selecting yes or no) in order to develop their observational skills and to encourage them to identify positive child behaviours. For example, at the end of chapter two (praising positive behaviour), parents are prompted to watch a video of a parent giving her child a specific labelled praise, and then answering three questions based on the video: (1) Did the parent praise the child immediately? (2) Was the parent close to the child when praising? (3) Did the parent share positive feelings when praising? A score out of three and the correct answers are provided for the responses to the videos. Each chapter ends with a multiple-choice quiz to test parents' knowledge and understanding of key principles. Parents will be given online automated feedback based on their quiz scores in addition to the correct answers. Parents also have an option to download and print a summary sheet for each chapter.

Parents will be given an opportunity to receive text message prompts to help keep them on track. If they would like to receive text messages, they will be asked at the beginning of the programme to enter their mobile phone number. The programme is fully automated, and the research team will have no contact with parents during the intervention. The centre administrator can be contacted if parents require any technical assistance during the study. A text message will be sent 5 days after the completion of a chapter informing the parent that the next chapter is now available. If the parent has not logged into the programme to complete the next chapter 3 days after it becomes available, a reminder text will be sent prompting them to $\log$ in and complete the next chapter. If a parent still has not logged in, weekly reminders will be sent. LifeGuide does not allow researchers to track how many messages parents have received, however, researchers will calculate the number of text messages each participant has received depending on the programme schedule, for example, if a parent has not logged on after 3 days of the chapter becoming available they will have received one text message, etc. Therefore, it will be possible to monitor the level of prompting each participant receives.

Baseline data will be collected prior to randomisation and, once completed, intervention parents will receive a notification of their status and their log in details, while parents in the wait-list control group will be informed that they will have access to the programme after 3 months. Follow-up data will be collected after 3 months regardless of whether intervention parents have completed the programme. Once postintervention data have been collected, control parents will receive their log in details for the programme. On completion of both baseline and follow-up visits, families will receive a children's book as a thank you for their time. On completion of all measures, parents will receive a copy of 'The Little Parent Handbook'. Data collection will begin in April 2016 and end in February 2017. 


\section{Primary measure}

The primary outcome is to establish whether the online parenting programme produces significant changes in positive parenting practices from baseline to follow-up as recorded using the Dyadic Parent-Child Interaction Coding System (DPICS). The researcher will observe the parent and child engaging in child-led play for $30 \mathrm{~min}$. This coding system was specifically designed to assess the quality of parent-child social interaction. ${ }^{37}$ The DPICS has demonstrated high inter-rater reliability for parent and child behaviours, $r=0.67-1.0$ and $r=0.76-1.0$, respectively. ${ }^{37}$ Direct observation was selected as the primary outcome as direct observational methods provide a more precise account of behaviour defined by the researcher and not the parent. ${ }^{38}$ Additionally, this observational measure has been used in a number of previous studies at the centre. ${ }^{32} 3940$

There are eight DPICS parent categories summarised in terms of positive and negative parenting. Positive parenting categories comprise direct command, labelled praise, unlabelled praise and descriptive commenting/ verbal labelling. Negative parenting categories comprise indirect command, questions, critical statement and negative command. No child categories will be recorded; child behaviour will be measured using the parent report ECBI only, as the main purpose of this study is to see whether the intervention has an affect on parental behaviour. Observational coding is continuous and records the total frequency of each category of parent behaviour for a total of $30 \mathrm{~min}$. Inter-rater levels of reliability will be assessed for $20 \%$ of all observations at all three time points.

\section{Secondary measures}

The following secondary outcomes will be collected at three time points by the research team for the intervention group and at two time points for the wait-list control group.

- Child behaviour as measured by the ECBI. ${ }^{30}$ This measure is a 36 -item inventory completed by the parent to assess the frequency and intensity of child behavioural problems for children aged 2-16 years, and has been used in many previous trials including several that have been conducted at the centre. ${ }^{31} 39$ Factor analyses of the ECBI for both children and adolescents indicate that it is a unidimensional measure of conduct problem behaviours. ${ }^{30}$

- Parenting practices as measured by the Arnold O'Leary Parenting Scale. ${ }^{41}$ This is a 30 -item inventory with three subscales measuring parental behaviour: laxness, over-reactivity and verbosity. Responses are recorded on a 7-point scale with two alternative responses to a particular parental situation. The parenting scale has been shown to exhibit adequate internal validity and test-retest reliability ${ }^{41}$ in addition to demonstrating significant correlations with observational measures of child problem behaviour. ${ }^{41}$
- Parental confidence as measured by the Parental Sense of Competence questionnaire. ${ }^{42}$ This 17 -item Likert-scale questionnaire measures competence on two separate dimensions: satisfaction and efficacy. The satisfaction questions measure parental anxiety, motivation and frustration (eg, "sometimes I feel like I'm not getting anything done") and the efficacy question examine competence, capability levels and problem-solving skills (eg, "I meet my own personal expectations for expertise in caring for my child") in relation to parenting. ${ }^{42}$ Ohan $e t$ a $t^{43}$ replicated the factor structure of the Parenting Sense of Competence Scale produced by Johnston and Mash, ${ }^{42}$ and provided evidence that the satisfaction and efficacy scales from this measure assess distinct aspects of parenting self-esteem.

- Parental mental health as measured by the General Health Questionnaire (GHQ) ${ }^{44}$ This is a 30 -item questionnaire and each item invites one of four responses in order to assess psychiatric symptoms including social dysfunction, sleeping patterns and depression. ${ }^{45}$ The responses include 'better than usual', 'same as usual', 'less than usual' and 'much less than usual' to questions such as 'have you found everything getting on top of you?' and 'have you been getting edgy and bad tempered?' This measure was used as research has demonstrated the association between maternal mental health and child conduct problems. ${ }^{46}$ Reliability coefficients of the questionnaire have ranged from 0.78 to 0.95 in various studies. ${ }^{47}$ There have been several factor analyses of the GHQ-30 in relatively large community samples. ${ }^{46}$

\section{Demographic information}

Demographic information will be collected from all participants at baseline prior to randomisation. The demographic questionnaire is based on the 'Personal Development and Health Questionnaire, ${ }^{48}$ and will include data on socioeconomic status, including poverty, parental educational level and single-parent status. The questionnaire will cover the following information:

Age of parent and child, gender of parent and child, child diagnosis, parent's relationship to the child (biological or non-biological parent), parent's age at birth of first child, how many children the parent has, ages of all children, parent's current relationship status, partner's relationship to the child, housing situation, employment status, income, parent's level of education and whether they have previously attended a parenting course. An additional question regarding their internet usage is also included.

\section{Data collection}

Members of the research team will collect parental self-report measures and observational data on parent-child interaction using the DPICS behaviour coding system, during home visits at baseline and follow-up. There is a possibility that parents will drop out of the programme 
before the end; nonetheless, all efforts will be made by researchers to collect follow-up data in the form of telephone contact and appointment letters. Parents will also be asked to complete a short feedback/satisfaction questionnaire at the end of the study to share their views of the programme.

The DPICS has been used in a number of studies evaluating parenting programmes. ${ }^{39} 4147$ Research team members are already trained in DPICS coding and have reached $80 \%$ inter-rater reliability across all categories. At least two coders, to establish inter-rater reliability, will code $20 \%$ of observations at each time point simultaneously (baseline and follow-up). Frequent practice sessions and meetings will be held to discuss any matters arising and to ensure maintenance of a minimum level of $80 \%$ reliability.

\section{Sample size}

The intention is to enrol 60 parents of children aged 3-8 years (40 to intervention and 20 to wait-list control, randomised on a 2:1 ratio). Due to limited funds and time restrictions associated with recruitment and data collection, a larger sample size would be difficult to recruit within the time frame. Additionally, this is a pilot RCT with the aim of exploring initial outcomes (in terms of measures, delivery and acceptance of the programme) with a view to conducting a larger scale trial in the future. Results from this pilot trial will give researchers initial information regarding acceptability and delivery of the programme with parents of children aged $3-8$ years and should be sufficient to explore initial outcomes in terms of encouragement in the use of positive parental strategies that would inform a power calculation for a larger definitive study.

\section{Randomisation}

Once all of the data for individual parents have been collected at baseline, parents will be randomised to either the intervention or a wait-list control condition on a 2:1 ratio (see figure 1). This allows for the evaluation of a larger intervention sample while also reducing the number of parents waiting for the intervention. This design is favoured for research in this field. ${ }^{39} \mathrm{~A}$ control condition was favoured over an alternative treatment condition as the researchers wanted to ensure that all participants received access to the intervention. The randomisation will be stratified according to child age (3-5 and 6-8 years) and gender (male and female) using the online software 'sealed envelope'. The centre administrative assistant will undertake the randomisation process, which will require entering the participant identification number, child age and child gender. The software will then generate the decision on whether the participant has been allocated to the intervention (group 1) or control (group 2) condition. Parents will receive a letter from the administrator informing them of their group allocation and intervention parents will receive the link to the website and their $\log$ in details with this letter. Control parents will be informed that they will receive

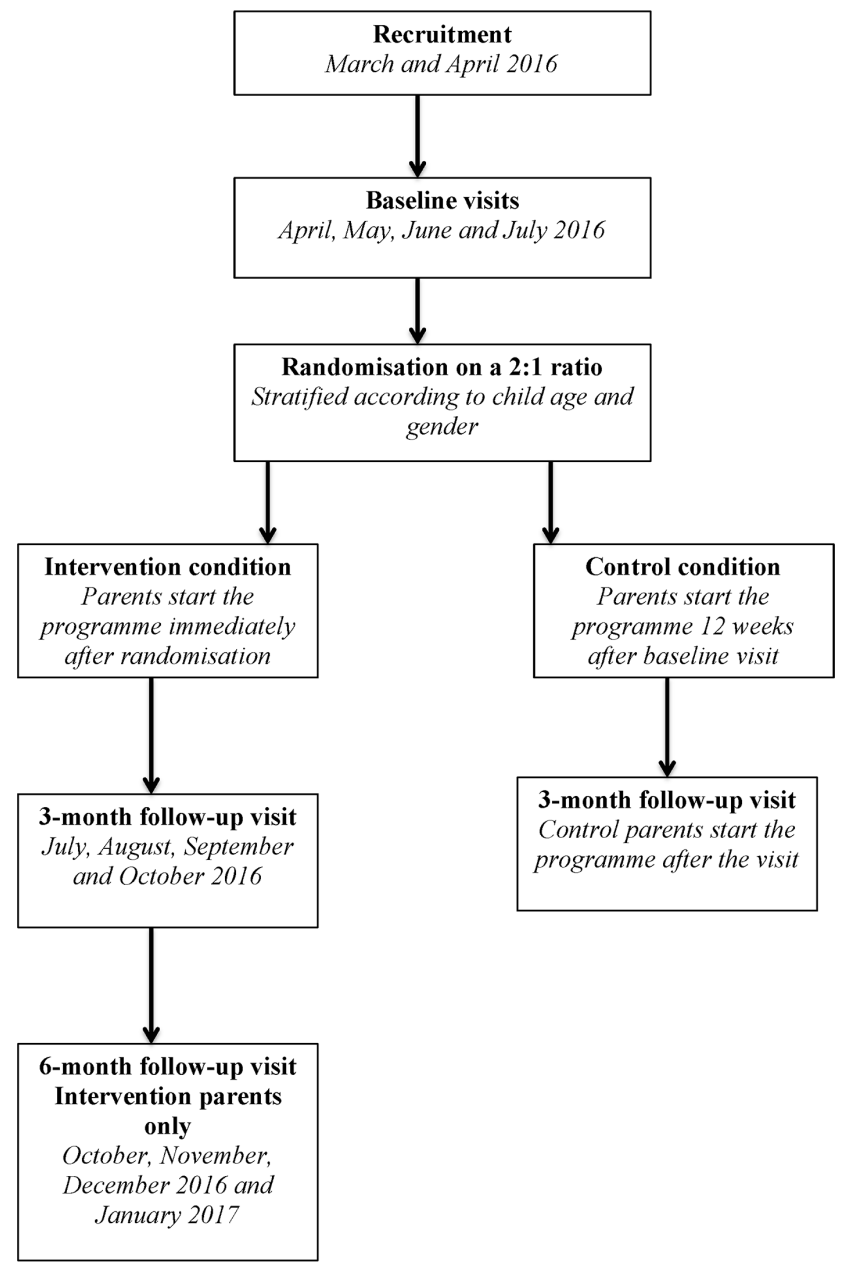

Figure 1 Participant flow chart.

their $\log$ in details on completion of the second home visit (postintervention data).

\section{Blinding}

Baseline measures will be completed prior to randomisation and parents will be asked (during home visits) not to reveal their group allocation to researchers in order, as far as possible, to keep the researchers blind to parent group allocation. However, some parents may reveal their allocation during the first follow-up home visit. In this instance, researchers will make a record of this. Due to the design of the study, it will not be possible to keep the researchers blind to group allocation at the 6-month follow-up stage as they will only involve intervention parents. However, the key measures are parent report questionnaires and the frequency-based behavioural observation that incorporates inter-rater reliability. If high levels of unmasking occur, a variable will be added to the analysis to control for this.

\section{Statistical analysis}

Baseline characteristics for all parents and children will be analysed and checked for differences (if any) between the intervention and wait-list control conditions. Any differences will be recorded and accounted for in the 
analysis. Analysis of covariance will be the main analysis method used to compare the intervention and wait-list control conditions. Any missing data will be treated using multiple imputation, a relatively flexible, general-purpose approach to dealing with missing data. ${ }^{49}$

\section{DISCUSSION}

This trial will provide information on the effectiveness of an online parenting programme, an intervention designed to increase positive parenting for parents of children aged 3-8 years. The effects of the intervention on child behaviour, parenting behaviour, parental mental health and parental sense of competence will also be assessed. It is hypothesised that the online programme will encourage parents to use positive parenting strategies, including spending more time with their child and praising and rewarding positive child behaviour. Additionally, it is hypothesised that the online programme will improve a range of outcomes including self-reported parenting practices, parental mental health, parental confidence and child behaviour.

This project is timely when considering the current situation with regards to rising numbers of children displaying behaviour problems, ${ }^{7}$ challenges faced by all parents and the known impact of parenting style on the establishment and maintenance child behaviour problems. ${ }^{124750}$ This programme could potentially be useful to parents who would like to receive additional support, but who are not living in targeted areas (such as Flying Start areas in Wales), where higher levels of parenting support are provided. A preventative universal programme available to all parents could potentially allow healthcare professionals more time and resources to target clinical (or at-risk) populations and also encourage parents to use well-established positive parenting strategies to prevent child behaviour problems from forming. A universal preventative programme such as this could be useful in encouraging positive parenting practices for all parents and reduce the number of families seeking advice for whom no service currently exists. ${ }^{51}$

Parents recruited to the trial will be notified of the results by means of a letter, and researchers will verbally present the findings to healthcare professionals who helped with recruitment. If the trial suggests that there are significant benefits, this would inform a bidfor funding for a larger definitive RCT with the goal that the intervention could subsequently be made available to parents in general as a preventative programme.

\section{Trial status}

The trial is currently ongoing. Baseline and 3-month follow-up measures for all parents were completed in October 2016. Data are currently being collected for the 6-month follow-up of intervention parents.

Contributors DAO : designing of the online programme, manuscript writing, gaining ethical approval, data collection, data analysis, critical revision and final approval of manuscript. NG : critical revision and final approval of manuscript.
$\mathrm{JH}$ : author of The Little Parent Handbook, critical revision and final approval of manuscript.

Competing interests $\mathrm{JH}$ is the author of 'The Little Parent Handbook'.

Ethics approval Betsi Cadwaladr University Health Board REC.

Provenance and peer review Not commissioned; externally peer reviewed.

Open Access This is an Open Access article distributed in accordance with the Creative Commons Attribution Non Commercial (CC BY-NC 4.0) license, which permits others to distribute, remix, adapt, build upon this work non-commercially, and license their derivative works on different terms, provided the original work is properly cited and the use is non-commercial. See: http://creativecommons.org/ licenses/by-nc/4.0/

(C) Article author(s) (or their employer(s) unless otherwise stated in the text of the article) 2017. All rights reserved. No commercial use is permitted unless otherwise expressly granted.

\section{REFERENCES}

1. Palmer S. Toxic childhood: how the modern world is damaging our children and what we can do about it. Orion, 2006.

2. Amato PR. The consequences of divorce for adults and children. Journal of Marriage and Family 2000;62:1269-87.

3. Cherlin AJ, Furstenberg FF, Chase-Lansdale L, et al. Longitudinal studies of effects of divorce on children in great Britain and the united states. Science 1991;252:1386-9.

4. Smith JD, Dishion TJ, Shaw DS, et al. Coercive family process and early-onset conduct problems from age 2 to school entry. Dev Psychopathol 2014:26:917-32.

5. Nixon RD. Treatment of behavior problems in preschoolers: a review of parent training programs. Clin Psychol Rev 2002;22:525-46.

6. Knapp M, McCrone P, Fombonne E, et al. The maudsley long-term follow-up of child and adolescent depression. The British Journal of Psychiatry 2002;180:19-23.

7. National institute for health and care excellence. Antisocial behaviour and conduct disorders in children and young people: recognition and management. https://www.nice.org.uk/guidance/cg158 (Accessed May 2013).

8. Foster EM, Jones DE. The high costs of aggression: public expenditures resulting from conduct disorder. Am J Public Health 2005;95:1767-72.

9. Wilson P, Furnivall J, Barbour RS, et al. The work of health visitors and school nurses with children with psychological and behavioural problems. J Adv Nurs 2008;61:445-55.

10. Williams M, Hutchings J. Health visitor feedback on a structured, behavioural training for working with families of children with behaviour problems. Manuscript submitted for publication 2017.

11. Gardner F, Burton J, Klimes I. Randomised controlled trial of a parenting intervention in the voluntary sector for reducing child conduct problems: outcomes and mechanisms of change. J Child Psychol Psychiatry 2006;47:1123-32.

12. Hutchings J. The little parent handbook. Bangor: Children's Early Intervention Trust, 2013.

13. Wantland DJ, Portillo CJ, Holzemer WL, et al. The effectiveness of Web-Based vs Non-Web-Based interventions: a Meta-Analysis of behavioral change outcomes. J Med Internet Res 2004;6:e40.

14. Bert SC, Farris JR, Borkowski JG. Parent training: implementation strategies for adventures in parenting. J Prim Prev 2008;29:243-61.

15. Jones DJ, Forehand R, Cuellar J, et al. Technology-Enhanced program for child disruptive behavior disorders: development and pilot randomized control trial. J Clin Child Adolesc Psychol 2014;43:88-101.

16. Office for national statistics. statistical bulletin. internet access Households and Individuals. London: Office for National Statistics, 2013.

17. Office for National Statistics. Statistical bulletin internet accesshouseholds and individuals. London: Office for National Statistics, 20162016.

18. Duggan M, Parents LA. And social media. Pew Research Centre. Retrieved from http://www.pewinternet.org/2015/07/16/parents-andsocial-media/ (accessed May 2015).

19. Netmums. https://netmums.com/home/about-us (accessed June 6th 2016).

20. Elgar FJ, McGrath PJ. Self-administered psychosocial treatments for children and families. J Clin Psychol 2003;59:321-39.

21. Taylor TK, Webster-Stratton C, Feil EG, et al. Computer-based intervention with coaching: an example using the incredible years program. Cogn Behav Ther 2008;37:233-46. 
22. Copeland J, Martin G. Web-based interventions for substance use disorders: a qualitative review. J Subst Abuse Treat 2004;26:109-16.

23. Strecher V, McClure J, Alexander G, et al. The role of engagement in a tailored Web-Based smoking cessation program: randomized controlled trial. J Med Internet Res 2008;10:e36.

24. Hustad JTP, Barnett NP, Borsari B, et al. Web-based alcohol prevention for incoming college students: a randomized controlled trial. Addict Behav 2010;35:183-9.

25. Brown J, Michie S, Geraghty AWA, et al. Internet-based intervention for smoking cessation (StopAdvisor) in people with low and high socioeconomic status: a randomised controlled trial. Lancet Respir Med 2014;2:997-1006.

26. Enebrink P, Högström J, Forster M, et al. Internet-based parent management training: a randomized controlled study. Behav Res Ther 2012:50:240-9.

27. Arden-Close EJ, Smith E, Bradbury K, et al. A visualization tool to analyse usage of Web-Based interventions: the example of positive online weight reduction (POWeR). JMIR Human Factors 2015;2:e8.

28. Ulfsdotter M, Enebrink P, Lindberg L. Effectiveness of a universal health-promoting parenting program: a randomized waitlistcontrolled trial of all children in focus. BMC Public Health 2014;14:1083.

29. Eyberg S, Robison E. Dyadic Parent-Child interaction coding system: a manual. University of Washington: The Parenting Clinic, 1981.

30. Eyberg S, Robison E. Conduct problem behaviour: standardisation of behavioural rating. J Clin Child Adolesc Psychol 1983;12:347-54.

31. Hutchings J, Appleton P, Smith M, et al. Evaluation of two treatments for children with severe behaviour problems: child behaviour and maternal mental health outcomes. Behav Cogn Psychother 2002;30:279-95.

32. Hutchings J, Lane E, Kelly J. Comparison of two treatments for children with severely disruptive behaviours: a four-year follow-up. Behav Cogn Psychother 1999;32:15-30.

33. Lane $\mathrm{E}$, Hutchings $\mathrm{J}$. Benefits of a course in behavioural analysis for health visitors. British Journal of Nursing 2002;11:702-14.

34. Yardley L, Osmond A, Hare J, et al. Introduction to the LifeGuide: software facilitating the development of interactive behaviour change internet interventions. Persuasive technology and digital behaviour intervention symposium. Edinburgh: GB, 2009.

35. Hare J, Osmond A, Yang Y, et al. LifeGuide: a platform for performing web-based behavioural interventions. Web-Science Society On-Line 2009:18-20.

36. Cooper J, Heron T, Heward W. Applied behaviour analysis. $2^{\text {nd }}$ ed. Upper Saddle River: NJ, 2007.
37. Robinson EA, Eyberg SM. The dyadic parent-child interaction coding system: standardization and validation. J Consult Clin Psychol 1981;49:245-50.

38. Aspland H, Gardner F. Observational measures of Parent-Child interaction: an introductory review. Child Adolesc Ment Health 2003;8:136-43.

39. Hutchings J, Gardner F, Bywater T, et al. Parenting intervention in sure start services for children at risk of developing conduct disorder: pragmatic randomised controlled trial. Bmj 2007;334:678.

40. Eames C, Daley D, Hutchings J, et al. The impact of group leaders' behaviour on parents acquisition of key parenting skills during parent training. Behav Res Ther 2010;48:1221-6.

41. Arnold DS, O'Leary SG, Wolff LS, et al. The parenting scale: a measure of dysfunctional parenting in discipline situations. Psychol Assess 1993:5:137-44.

42. Johnston C, Mash EJ. A measure of parenting satisfaction and efficacy. J Clin Child Psychol 1989;18:167-75.

43. Ohan JL, Leung DW, Johnston C. The parenting sense of competence scale: evidence of a stable factor structure and validity. Can J Behav Sci 2000;32:251-61.

44. Goldberg D. Manual of the general health questionnaire. Windsor: England, 1978.

45. Huppert FA, Walters DE, Day NE, et al. The factor structure of the general health questionnaire (GHQ-30). A reliability study on 6317 community residents. Br J Psychiatry 1989;155:178-85.

46. Jackson $\mathrm{C}$. The general health questionnaire. Occup Med 2007;57:79.

47. Hutchings J, Bywater T, Williams ME, et al. Improvements in maternal depression as a mediator of child behaviour change. Psychology 2012;03:795-801.

48. Hutchings J. The personal and parental characteristics of preschool children referred to a child and family mental health service and their relation to treatment outcome (Doctoral dissertation, University of Wales). 1996.

49. Sterne JAC, White IR, Carlin JB, et al. Multiple imputation for missing data in epidemiological and clinical research: potential and pitfalls. Bmi 2009;338:b2393.

50. Gardner F, Hutchings J, Bywater $\mathrm{T}$, et al. Who benefits and how does it work? moderators and mediators of outcome in an effectiveness trial of a parenting intervention. $J$ Clin Child Adolesc Psychol 2010;39:568-80.

51. Lingley-Pottie P, McGrath P. Distance therapeutic alliance: the participant's experience. Advances in Nursing Science 2007;30:353-66. 